\title{
OTIMIZAÇÃO NO GERENCIAMENTO DO FLUXO DE CAIXA DE UMA EMPRESA DO SETOR DE MATERIAL ESCOLAR ${ }^{1}$
}

\author{
Giovanni Margarido Righetto ${ }^{\mathrm{a}}$, Reinaldo Morabito ${ }^{\mathrm{a}^{*}}$

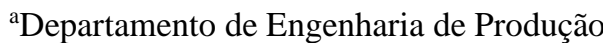 \\ Universidade Federal de São Carlos - UFSCar, São Carlos-SP, Brasil
}

Recebido 30/04/2020, aceito 07/01/2021

\begin{abstract}
RESUMO
Neste artigo estuda-se um problema de otimização no gerenciamento do fluxo de caixa em tesourarias de empresas. Embora seja motivado por uma empresa do setor de material escolar, esse problema também aparece em outras empresas deste e de outros setores. Neste estudo ele é representado por redes de fluxos com ganhos e perdas que definem os fluxos financeiros no tempo e formulado matematicamente por meio de programação linear inteira mista. Para ilustrar a aplicação do modelo de otimização, utilizou-se o caso do fluxo de caixa de uma empresa típica do setor de material escolar que envolve diferentes períodos de carência para o resgate de aplicações financeiras com rendimentos lineares por partes. Os resultados obtidos são promissores e mostram que as soluções do modelo são tão boas, ou melhores, do que a soluções da tesouraria, indicando que essa abordagem pode ser útil para apoiar decisões de gestão de caixa na prática.
\end{abstract}

Palavras-chave: Fluxo de caixa, Programação inteira mista, Fluxos em rede, Carência.

\begin{abstract}
This paper studies an optimization problem in the cash flow management of company treasuries. Although motivated by a company of the stationary sector, this problem also appears in other companies of this and other sectors. In this study, it is represented as network flows with gains and losses that define the financial flows over time and it is mathematically formulated as a mixed integer programming model. To illustrate the model application, the case of the cash flow of a typical stationary company, which involves different grace periods with piecewise linear yields, is used. The results obtained are promising and show that the model solutions are as good as, or better than, the solutions of the treasury, indicating that this approach can be useful for supporting decisions in practice.
\end{abstract}

Keywords: Cash flow, Mixed integer programming, Network flows, Grace periods.

*Autor para correspondência. E-mail: morabito@ufscar.br.

DOI: 10.4322/PODes.2021.010 


\section{Introdução}

Este artigo propõe uma abordagem de otimização baseada em programação linear inteira mista para apoiar decisões na gestão do caixa de empresas de material escolar. O trabalho foi motivado por um caso estudado em uma típica empresa deste setor para que a sistematização da tomada de decisão seja rápida e não dependente de experiência dos analistas da companhia. A sistematização faz com que os resultados sejam apresentados quase que instantaneamente e várias simulações podem ser analisadas em pouco tempo, variando-se os parâmetros do modelo e analisando-se diferentes cenários. No método utilizado na empresa, os resultados são gerados em algumas horas, já que são realizados por tentativa e erro em planilhas eletrônicas pelos analistas responsáveis. Os resultados deste artigo auxiliam na tomada de decisão financeira de alocação de caixa entre alternativas de aplicação e captação de recursos financeiros de empresas do setor de material escolar. Essa abordagem de otimização também pode ser útil para empresas de outros setores com problemas de caixa similares.

O modelo matemático aqui desenvolvido é uma extensão das formulações de fluxos em redes desenvolvidas por Golden et al. (1979) e Pacheco e Morabito (2011). Por exemplo, essa formulação estendida considera empréstimos bancários e a inserção de um conjunto de arcos que representam uma aplicação financeira em títulos negociáveis com dois ou mais períodos de carência e com rendimentos lineares por partes, que não foram considerados nas formulações anteriores e que são relevantes para empresas do setor de material escolar. Algumas particularidades importantes da empresa aqui estudada são: (i) manter um saldo mínimo de caixa e de investimentos em ativos com liquidez imediata. Apesar do custo de oportunidade perdido, essa forma de gestão do caixa protege a companhia de eventos econômicos adversos que podem, eventualmente, ocorrer. Esses eventos geralmente vêm acompanhados de uma redução de crédito na economia e podem resultar em deficiências de caixa ou aumento significativo do custo de captação de recursos para o capital de giro das companhias. (ii) A possibilidade de investir recursos financeiros em ativos com mais de um período (e.g., dois meses) de carência para o resgate.

Outra característica de empresas do setor de material escolar é a captação de recursos por meio do sistema bancário. A empresa estudada tem um bom rating de crédito junto ao sistema bancário e é capaz de financiar as suas operações com empréstimos bancários, quando necessário. O rating de crédito de uma empresa é uma informação pública que representa o julgamento de analistas de crédito a respeito da capacidade das empresas em honrar seus compromissos financeiros (Damasceno et al., 2008). Essas características e particularidades de empresas desse setor foram levadas em conta para a formulação e aplicação do modelo de otimização aqui proposto.

O presente estudo pretende contribuir para a prática de pesquisa operacional e foi conduzido seguindo o método clássico de resolução de problemas por meio de pesquisa operacional, ou seja, envolvendo as fases de definição acurada do problema, construção de um modelo matemático representativo, solução do modelo utilizando métodos adequados e validação da abordagem para avaliar seu desempenho na prática. Na Seção 2, apresenta-se uma breve revisão da literatura relacionada aos modelos de gestão do fluxo de caixa e na Seção 3, o problema é definido e representado por um modelo determinístico linear inteiro misto. Na Seção 4, discute-se o caso da empresa estudada típica desse setor e aplica-se a abordagem para tratar situações com dados reais do estudo de caso, apresentando-se resultados computacionais e análises desses resultados. Na Seção 5, apresentam-se as conclusões e considerações finais sobre o trabalho desenvolvido, incluindo discussões de perspectivas de pesquisas futuras.

\section{Revisão da Literatura}

O gerenciamento do caixa lida com o uso eficiente dos ativos líquidos de uma companhia e foi uma das primeiras áreas de aplicação da programação matemática e da pesquisa operacional (Mulvey, 1994). Existe uma ampla literatura sobre técnicas de pesquisa operacional aplicadas a problemas relacionados à engenharia financeira. Alguns desses trabalhos podem ser encontrados em Ashford et al. (1988), Mulvey e Vladimirou (1992), Steuer e Na (2003), Geunes e Pardalos (2003), Gupta e Dutta (2011), Pacheco e Morabito (2011), Alimardani (2014), Righetto et al. 
(2016), Yu et al. (2017), Ahmad et al. (2018), Tabei et al. (2019), Schoeder e Kacem, (2019), Righetto et al. (2020), Schroeder e Kacem (2020) e nas referências neles citadas. No gerenciamento do caixa, além de lidar com os problemas de obtenção de fontes de recursos financeiros, faz-se necessário definir as regras para o controle do nível do saldo de caixa e a administração de um conjunto de fatores que estão estruturados no tempo (Sethi e Thompson, 1970; Welsch et al., 1988; Van Horne, 1995; Gitman, 1997; Brigham e Houston, 2004; Salas-Molina et al., 2019).

Ao otimizar os processos financeiros, as semelhanças com os fluxos em redes são naturais devido aos seus sistemas de fluxos de caixa serem inter-relacionados e possuírem parâmetros e variáveis com relações complexas e numerosas (Crum et al., 1979; Crum e Nye, 1981; Geunes e Pardalos, 2003). Em particular, os modelos de gestão de fluxo de caixa podem ser formulados como modelos de fluxo em redes generalizadas, em que os fluxos em arcos da rede podem ter ganhos ou perdas (Golden et al., 1979; Crum et al., 1979; Srinivasan e Kim, 1986; Mcbride e O’Leary, 1997).

Segundo Sousa e Barros (2000), existem diversas tentativas de se criar um modelo matemático que seja capaz de equilibrar o caixa de uma empresa, minimizar o custo de sua gestão ou, então, maximizar o valor de uma empresa. Os mesmos autores salientaram que os modelos mais comumente encontrados tratam o caixa como um estoque e, por essa analogia, criam condições para a otimização do trade-off entre os custos de se manter caixa adicional e os relacionados à sua falta. Baumol (1952) elaborou um modelo para o gerenciamento de caixa, que atribui ao fluxo de dinheiro em uma companhia o mesmo tratamento dado àquele que se atribui quando da gestão dos estoques físicos de uma empresa. Beranek (1963) e Scherr (1989) trataram o problema de fluxo de caixa considerando as entradas de caixa constantes e os pagamentos ocorrendo de forma concentrada em determinados períodos de tempo. O tratamento dado a esses modelos também utiliza a metodologia utilizada por Baumol (1952). Outros modelos que utilizam esse tipo de metodologia podem ser encontrados em Tobin (1956), Robicheck et al. (1965) e Calman (1968).

Robichek et al. (1965) desenvolveram um modelo para a tomada de decisões de financiamento de curto prazo por meio da programação linear, abordando o fato de quanto e de quando obter recursos de um grupo de fontes de terceiros. Nesse modelo, um saldo mínimo de caixa é especificado para todos os períodos. A função objetivo do problema de programação linear indica como obter os fundos necessários indicados pelo orçamento de caixa ao custo mínimo total e está sujeita às restrições impostas pelas alternativas de financiamento. Srinivasan e Kim (1986) colocam o modelo de Robichek et al. (1965) como tendo sido a base para diversos refinamentos subsequentes no tratamento do problema da gestão do caixa. Contudo, entendem que não foram tratados dois aspectos importantes do problema da gestão do caixa: as transações de investimento de curto prazo e as considerações sobre o saldo mínimo de caixa.

Orgler (1969) abordou o problema da gestão do caixa por meio de um modelo de programação linear multi-período, que inclui quatro tipos principais de variáveis de decisão: programação de pagamentos, financiamento de curto prazo, o saldo de caixa e transações com títulos para os quais tanto o montante quanto o vencimento são explicitamente definidos e, consequentemente, derivados do modelo. As características intertemporais do modelo estão baseadas em um planejamento de caixa anual dividido em dez períodos diários, cinco períodos de dez dias e dez períodos mensais. No modelo de Orgler (1969), são tratados sete tipos de restrições: os pagamentos, o financiamento de curto prazo, as vendas de títulos negociáveis, o saldo de caixa, o fluxo de caixa, o encerramento e os índices financeiros. A função objetivo do modelo pode ser formulada de diversas maneiras. A alternativa escolhida por Orgler (1969) foi maximizar o valor das receitas líquidas obtidas a partir das transações de caixa durante o período de planejamento. Qualquer montante de receita gerado pelo modelo é imediatamente considerado para reinvestimento, ao mesmo tempo em que todo custo é financiado. Por consequência, pela adição dos retornos líquidos do início ao fim do período de planejamento, a função objetivo representa o valor da receita líquida do orçamento de caixa no horizonte de planejamento.

Srinivasan (1974) utilizou a mesma abordagem desenvolvida por Orgler (1969) para tratar o problema de gestão do caixa, porém formulou o problema como um modelo de transbordo. Modelos de transbordo de programação linear podem ser resolvidos eficientemente por meio de algoritmos específicos de fluxos em redes (Srinivasan e Kim, 1986). A adaptação do modelo de 
transbordo ao problema de gestão do caixa faz com que os depósitos sejam tratados como origens de recursos e os mercados como aplicações. $\mathrm{O}$ modelo de transbordo aplicado à gestão do caixa visa minimizar o custo total de alocação das fontes de recursos às diferentes aplicações, mantendo a possibilidade da transferência de caixa entre as origens (Srinivasan, 1974). O problema formulado por Srinivasan (1974) consiste em decidir de forma ótima sobre: a programação dos pagamentos para as compras previstas nos períodos determinados; as transações a fazer na carteira de títulos mantidos pela firma no início do período de planejamento; a opção sobre novos investimentos em títulos; e o uso da linha de crédito disponível. Golden et al. (1979) colocaram como uma séria desvantagem ao uso do modelo o fato de que a capitalização dos juros e o reinvestimento dos rendimentos obtidos não serem diretamente considerados. Devido a esse fato, o valor máximo da função objetivo fica subestimado. Essa desvantagem se intensifica na medida em que o horizonte de planejamento se estende.

Mais relevante ainda é o fato de que o modelo de Srinivasan (1974) pode indicar inviabilidade da solução em situações em que essa inviabilidade não existe. Golden et al. (1979) usaram um fluxo de caixa com três períodos para exemplificar a ocorrência desse tipo de erro de conclusão gerada a partir do modelo de Srinivasan. No exemplo citado, os resultados obtidos com um aumento de $25 \%$ na demanda por caixa do terceiro período acusam inviabilidade. No entanto, se forem computados os rendimentos de juros nos três períodos, observa-se que são gerados fundos suficientes para o atendimento ao aumento da demanda (Golden et al., 1979).

Mulvey e Vladimirou (1992) consideram que os modelos de redes generalizadas tratam de um tema comum: a alocação de fundos em diversas categorias de ativos durante vários períodos. Um modelo de rede generalizada é construído pela associação de um nó da rede a cada ativo, em determinado período, e um arco é associado a cada decisão de transação. Cada arco deve ter um multiplicador associado que aumenta ou diminui o fluxo no arco. O fluxo que entra no arco é ampliado ou reduzido em determinada proporção pelo multiplicador, antes de atingir o próximo nó. Desse modo, taxas de câmbio, de retorno e de empréstimo são modeladas por meio dos multiplicadores dos arcos na estrutura de rede generalizada. Jorjani e Lamar (1994) propuseram incorporar o conceito de desconto baseado em quantidade ao problema de gerenciamento do fluxo de caixa. A ideia central é que é possível obter descontos ou adicionais de rendimento, de acordo com o volume de dinheiro que está sendo negociado, quer estejam envolvidos os parâmetros de custo ou de remuneração do capital. A complexidade desse tipo de desconto deriva da natureza não linear da função custo, que representa o desconto baseado na quantidade. Como efeito do desconto dado, os custos marginais diminuem à medida que o fluxo de dinheiro aumenta. Então, esse tipo de problema de fluxo em rede não pode ser convertido em um problema equivalente de fluxo em rede com arcos de custos lineares e requer procedimentos de solução específicos (Jorjani e Lamar,1994).

O modelo de Golden et al. (1979), aprimorado por Pacheco e Morabito (2011), que é a base para o modelo determinístico desenvolvido neste artigo, pode ser expresso por um número $\boldsymbol{n}$ de períodos de mesmas ou diferentes durações e várias classes de ativos de diversos níveis de liquidez, o que se busca é maximizar o retorno do caixa no horizonte de planejamento. Para facilitar a exposição, os autores trabalharam com o caso de dois ativos, sem perda de generalidade. $\mathrm{O}$ ativo $\boldsymbol{x}$ é utilizado como meio de troca, ou seja, $\boldsymbol{x}$ é dinheiro, enquanto o ativo $\boldsymbol{y}$ é facilmente conversível em dinheiro, mas a um custo positivo. Os pressupostos da modelagem em questão são: (i) o ativo $\boldsymbol{x}$ é mais líquido do que o ativo $\boldsymbol{y}$; (ii) os pagamentos devem ser realizados apenas com o ativo $\boldsymbol{x}$, pois somente o ativo $\boldsymbol{x}$ é aceitável como um meio de troca; (iii) as entradas e saídas de caixa em todos os períodos são determinísticas; (iv) o estoque inicial do ativo $\boldsymbol{y}$ também é conhecido; (v) os ativos $\boldsymbol{x}$ e $\boldsymbol{y}$ podem ser convertidos um no outro e existe custo unitário de conversão; (vi) as conversões são consideradas instantâneas; e (vii) todas as entradas ocorrem no início de um período e as saídas ocorrem no fim do período. Conforme mencionado, os períodos podem ter a mesma duração, ou durações diferentes.

Abaixo são definidos os parâmetros do modelo:

- $\alpha$ : taxa de juros (rendimento) por período do ativo $x$;

- $\beta$ :taxa de juros (rendimento) por período do ativo $y$; 
- $c_{x, y}$ : o custo de conversão por unidade do ativo $x$ para ativo $y$;

- $\quad c_{y, x}$ : o custo de conversão por unidade do ativoy para ativo $x$;

- $x_{0}$ : saldo inicial do ativo $x$;

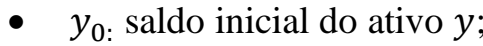

- $s_{t}$ : oferta do ativo $x$ no período de tempo $t(t=1,2, \ldots, n)$;

- $d_{t}$ : demanda do ativo $x$ no período de tempo $t(t=1,2, \ldots, n)$.

Figura 1: Rede de Fluxos entre as opções 1 e 2 nos períodos 1, 2, .., $n$

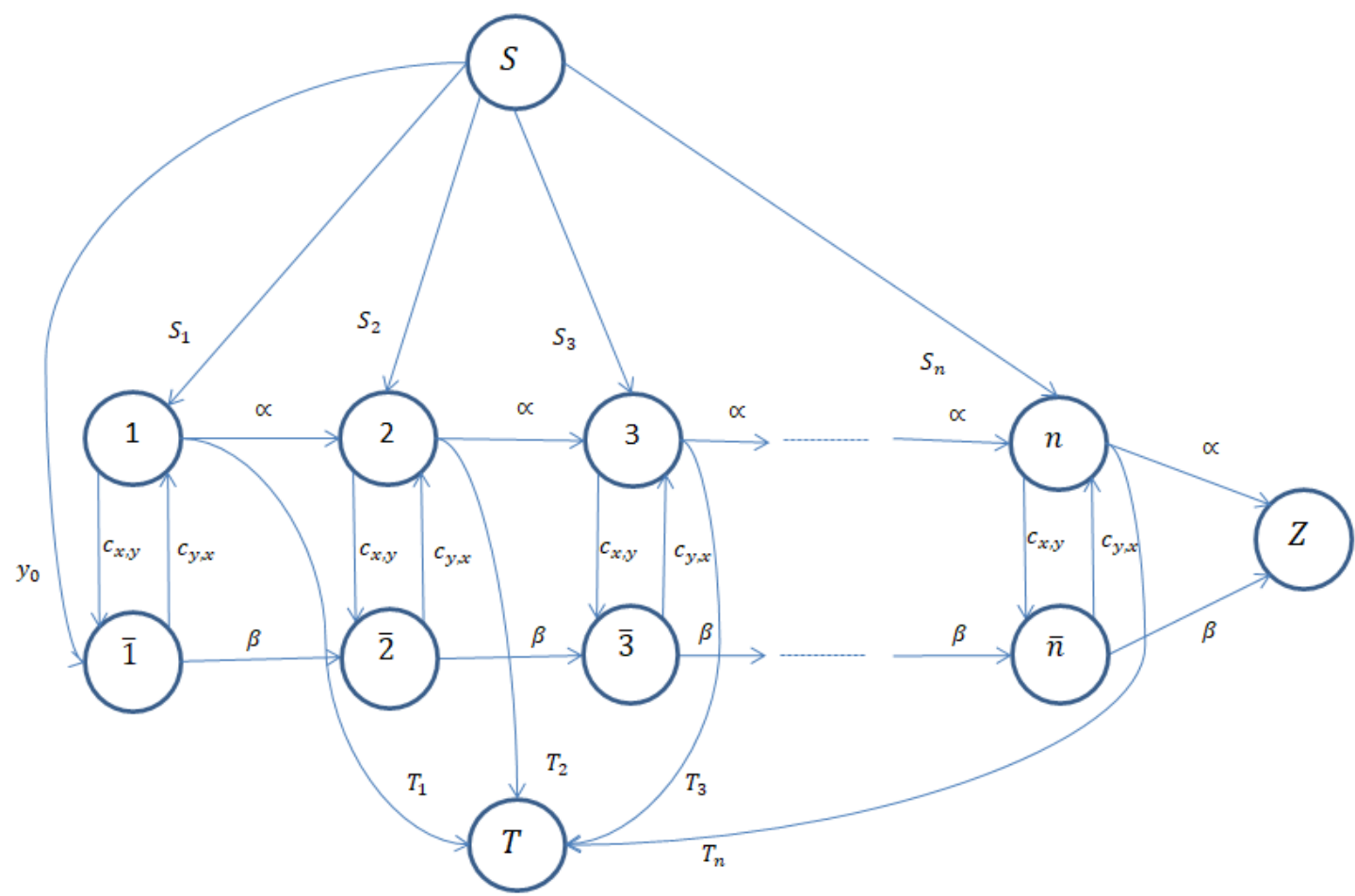

Fonte: Golden et al., 1979.

Uma rede $G=(N, A, W)$ consiste de um conjunto de nós $N$, um conjunto de arcos orien$\operatorname{tados} A$ e pesos ou multiplicadores $\operatorname{dos} \operatorname{arcos}(i, j) \in A$, dados pela matriz $W=\left[w_{i j}\right]$. Considere o fluxo da Figura 1, que modela um problema de fluxo de caixa com $n$ períodos. Neste exemplo, $N=\{S, T, Z, 1,2, \ldots, n, \overline{1}, \overline{2}, \ldots, \bar{n}\}$. O nó $S$ é um nó de entrada de caixa e o nó $T$ é um nó de saída de caixa. O nó $Z$ é o nó objetivo, no sentido de que o objetivo é maximizar o fluxo para esse nó. Os nós $1,2, \ldots n$ e $\overline{1}, \overline{2}, \ldots, \bar{n}$ significam o horizonte de tempo $t$ para o ativo $x$ e $y$, respectivamente. O conjunto $A$ inclui os $\operatorname{arcos}(S, t)$ e $(t, T), t=1,2, \ldots n$, onde os parâmetros $s_{t}$ e $d_{t}$ indicam fluxos de caixa fixos em cada período $t$. Os parâmetros $s_{t}$ e $d_{t}$, embora conhecidos, não são necessariamente constantes de um período para o outro. As entradas de caixa estão posicionadas nos arcos deixando o nó $S$ com destino aos respectivos nós do ativo $x$ em cada período $t$, enquanto que as saídas de caixa estão posicionadas entre os nós do ativo $x$ e o nó $T$. O conjunto $A$ também inclui os arcos horizontais $(t, t+1), t=1,2, \ldots, n-1$, e $(\bar{t}, \bar{t}+1), \bar{t}=\overline{1}, \overline{2}, \ldots, \bar{n}-1$, indicando investimentos de recursos em cada ativo, em cada período e os arcos verticais $(t, \bar{t})$ e $(\bar{t}, t)$ representando as conversões de recursos entre os dois níveis de liquidez. Os outros arcos do conjunto $A,(n, Z)$ e $(\bar{n}, Z)$, correspondem ao fluxo do último período dos ativos $x$ e $y$ para o nó $Z$. O conjunto $N^{-}$é definido como os nós do conjunto $N$ sem os nós $S$ e $T$, ou seja, $N^{-N\{S\}\{T\}}$.

As variáveis de decisão do modelo são definidas como:

- $f_{i j}$ : fluxo de entradas no $\operatorname{arco}(i, j) \in A, i \in N^{-, j \in N^{-}}$

- $g_{i j}$ : fluxo de saídas do $\operatorname{arco}(j, i) \in A, i \in N^{-, j \in N^{-}}$ 
Estas variáveis estão linearmente relacionadas por um multiplicador positivo $w_{i j}$ :

$g_{i j}=f_{i j} w_{i j} \quad$ para cada $\operatorname{arco}(j, i) \in A, i \in N^{-, j \in N^{-}(1)}$

A expressão (1) indica que o fluxo das saídas do arco $(j, i)$ aumenta (se $w_{i j}>1$ ), ou diminui (se $0<w_{i j}<1$ ) o fluxo das entradas nos arcos subsequentes. O multiplicador $w_{i j}$ representa o ganho ou perda de recursos (taxa de juros ou taxas de conversão). Baseado na Figura 1, os multiplicadores podem ser definidos como:

$$
w_{i j}=\left\{\begin{array}{c}
1+\alpha \operatorname{para}(i, j)=(t, t+1) \mathrm{ou}(n, Z) \wedge 1+\beta \operatorname{para}(i, j)=(\bar{t}, \overline{t+1}) \mathrm{ou}(\bar{n}, Z) \\
1-c_{x y} \operatorname{para}(i, j)=(t, \bar{t}) \\
1-c_{y x} \text { para }(i, j)=(\bar{t}, t) \\
\text { 1casocontrário }
\end{array}\right.
$$

O problema de gerenciamento do fluxo de caixa pode ser descrito pelo seguinte modelo de otimização linear com as variáveis $f_{i j}$ e $g_{i j}$ relacionadas por (1) e (2):

$$
\text { Maximizar } g_{n, Z}+g_{\bar{n}, Z}(3)
$$

sujeito a:

$$
\sum_{j \in N^{-},(i, j) \in A} f_{i j}-\sum_{j \in N^{-},(i, j) \in A} g_{j i}=\left\{\begin{array}{l}
s_{i}-d_{i}+x_{0} \text { para } i=1 \\
s_{i}-d_{i} \text { para } i=2, \ldots, n \\
y_{0} \text { para } i=\overline{1} \\
0 \text { para } i=\overline{2}, \overline{3}, \ldots, \bar{n}
\end{array}\right.
$$

$$
f_{j i} \geq 0 \text { parai } \in N^{-, j \in N^{-e(i, j) \in A(5)}}
$$

A função objetivo (3) maximiza o fluxo que chega no nó $Z$ no final do horizonte de planejamento. A restrição (4) estabelece o balanço de fluxo dos recursos financeiros em cada ativo para cada período, de forma que todo o fluxo de entrada em cada nó seja exatamente igual ao seu fluxo de saída. A restrição (5) estabelece que todas as entradas sejam não negativas. Substituindo $g_{i j}$ em (3)-(4) com (1), o modelo fica definido apenas em termos das variáveis de decisão $f_{i j}$. Uma análise do efeito do impacto da CPMF (Contribuição Provisória sobre Movimentações Financeiras) nas movimentações financeiras e do acréscimo dos empréstimos bancários no problema da gestão do fluxo de caixa utilizando um modelo similar à (3)-(5) pode ser encontrada em Pacheco e Morabito (2011).

\section{Descrição do Problema e Modelo Matemático}

Nesta seção descreve-se o problema aqui estudado da gestão do caixa da empresa típica do setor de material escolar e em seguida desenvolve-se um modelo matemático representativo para esse problema. A partir dos modelos de Golden et al. (1979) e Pacheco e Morabito (2011), é possível incorporar na programação matemática do fluxo em redes aplicações comuns na gestão financeira do caixa o saldo mínimo de caixa, a capacidade de tomar empréstimos e outros ativos com diferentes tipos de liquidez e aplicações financeiras que possuem prazo de carência no resgate, por exemplo. 


\subsection{Definição e Representação do Problema em Grafos}

Algumas particularidades devem ser consideradas na empresa do setor de material escolar. Por exemplo, conforme mencionado anteriormente, manter um saldo mínimo de caixa e de investimentos em ativos com liquidez imediata. Apesar do custo de oportunidade perdido, essa forma de gestão do caixa protege a companhia de eventos econômicos adversos que podem, eventualmente, ocorrer. Esses eventos geralmente vêm acompanhados de uma redução de crédito na economia e podem resultar em deficiências de caixa ou aumento significativo do custo de captação de recursos para o capital de giro das companhias.

Outra particularidade é a possibilidade de investir recursos financeiros em ativos com mais de um período (e.g., dois meses) de carência para o resgate. Esses títulos negociáveis são muito utilizados no mercado financeiros e fazem parte do portfólio de investimentos financeiros de muitas empresas. Eles podem ser eficientes para adequar os investimentos com a necessidade de liquidez das companhias e melhorar a relação risco e retorno das mesmas, com impacto interessante na maximização dos fluxos financeiros dessas empresas. Importante salientar que é possível incorporar ao modelo outros tipos de investimentos, como bolsa de valores, debentures e operações de renda fixa, por exemplo. Para isso devem ser incorporados arcos adicionais ao modelo. Além disso, outra característica da empresa do setor de material escolar é a captação de recursos por meio do sistema bancário. A empresa tem um bom rating de crédito junto ao sistema bancário e é capaz de financiar as suas operações com empréstimos bancários, quando necessário. O rating de crédito de uma empresa é uma informação pública que representa o julgamento de analistas de crédito a respeito da capacidade das empresas em honrar seus compromissos financeiros (Damasceno et al., 2008).

Similarmente à rede da Figura 1, a rede do presente problema de fluxo de caixa também pode ser representada por um grafo $G=(N, A, W)$, no qual $N$ é o conjunto de nós, $A$ é o conjunto de arcos conectando dois nós em $N$ e $W=\left[w_{i j}\right]$ é a matriz de multiplicadores para cada arco $(i, j)$. A Figura 2 representa um exemplo desta rede para o fluxo de caixa da companhia estudada, com o conjunto de nós $N=\{s, d, z, 1,2, \ldots, n, \overline{1}, \overline{2}, \ldots, \bar{n}, 1,2, \ldots, n\}$. Os nós de 1 a $n$ representam os nós do caixa (ativo $a$ ); os nós de $\overline{1}$ a $\bar{n}$ representam os nós do CDB (Certificado de Depósito Bancário) sem período de carência (ativo $b$ ); e os nós í a ń representam o CDB com período de carência (ativo $c$ ), que não foram considerados no modelo desenvolvido por Golden et al.(1979), nem em outros também baseados em Golden et al.(1979), como os modelos desenvolvidos por Pacheco e Morabito (2011). 
Figura 2: O fluxo em rede com arcos reversos indicando os empréstimos e as aplicações com carência para o resgate.

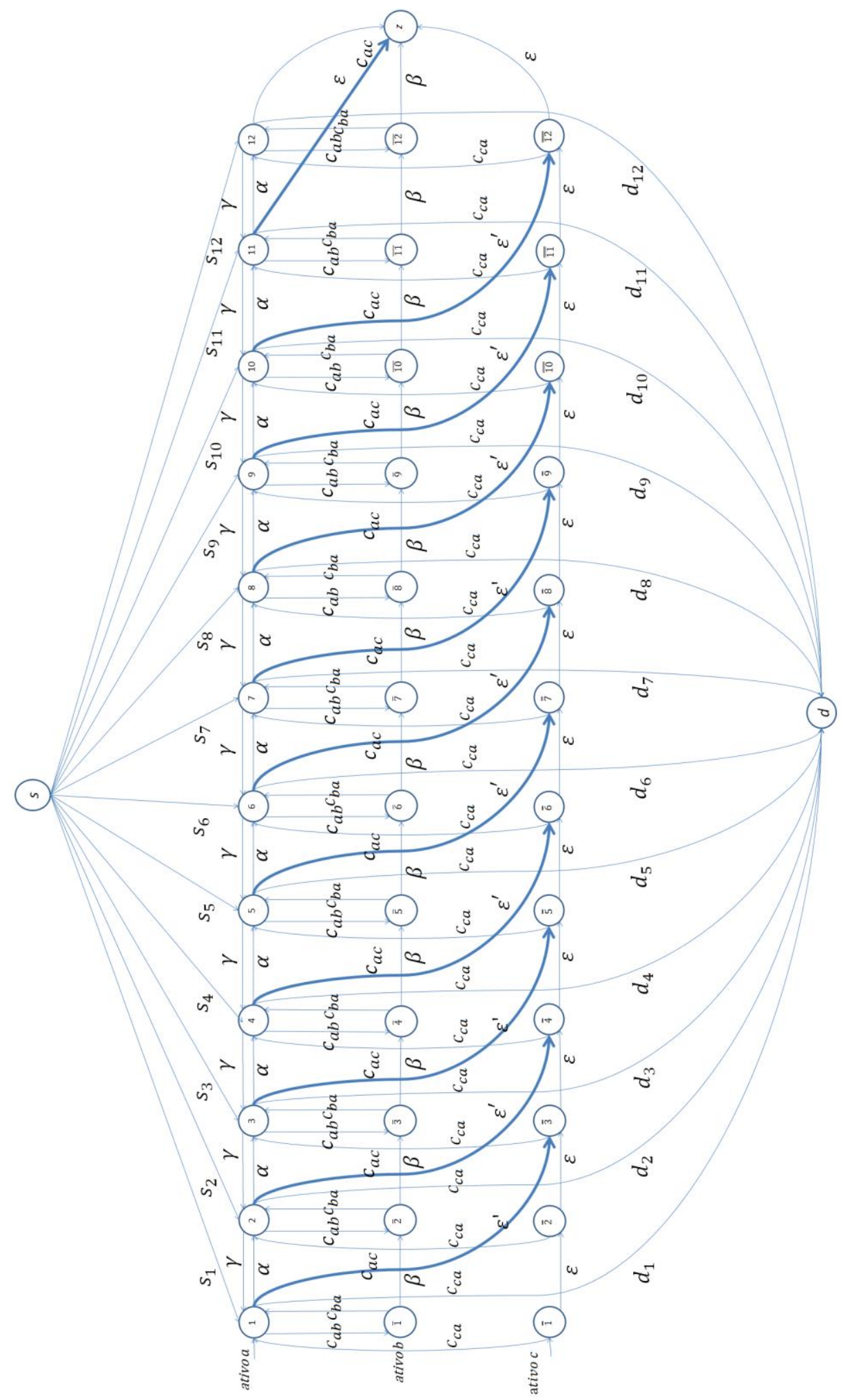

Fonte: Righetto et al., 2016.

O nó $s$ representa as entradas de caixa, enquanto o nó $d$ representa as saídas de 
caixa. O nó $z$ representa o nó objetivo, no qual o fluxo que chega nesse nó deve ser maximizado. Na aplicação financeira em CDB com período de carência, como os recursos financeiros ficam sem liquidez por dois períodos de tempo, o rendimento oferecido ao investidor é superior aquele com liquidez imediata. Observe na Figura 2, por exemplo, o arco que sai do nó 3 e chega no nó 5. Esse arco representa a aplicação financeira com período de carência para o resgate, no caso dois períodos. Observe também, na Figura 2, que no nó 5, os recursos financeiros estão liberados para o resgate. Essa liberação é representada pelo arco que sai de 5 e chega em 5. Essa também é uma das diferenças do modelo matemático desse trabalho em relação aos modelos propostos por Golden et al. (1979) e Pacheco e Morabito (2011).

Outra diferença importante desse modelo em relação aos desenvolvimentos anteriores é a consideração de rendimentos crescentes de acordo com o montante aplicado. $\mathrm{Ou}$ seja, se o valor da aplicação estiver entre zero e um limite superior previamente determinado, o rendimento obtido é menor do que aquele aplicado se o montante for superior a esse limite. Essa consideração pode ser formulada usando programação inteira mista para a sua solução, já que o problema é de maximização e a função que representa o valor do rendimento em função do valor aplicado é convexa e linear por partes.

A Figura 3 representa como a remuneração do ativo com carência para o resgate aumenta em função do valor investido. Observe na Figura 3 que se o valor investido for menor do que $l m_{i j}$, a sua remuneração é $w_{i j}$. Caso o valor investido seja maior ou igual do que $l m_{i j}$, a sua remuneração passa a ser $w_{i j}^{2}$, com $w_{i j}^{2}>w_{i j}$. Na figura, $f_{i j}^{1}$ é o montante investido menor que $l m_{i j}$, que recebe a rentabilidade representada pelo multiplicador $w_{i j}$, e $f_{i j}^{2}$ é o montante investido maior ou igual que $l m_{i j}$, que recebe a rentabilidade $w_{i j}^{2}$. Note na figura que $g_{i j}=w_{i j} f_{i j}^{1}+w_{i j}^{2} f_{i j}^{2}$ e $f_{i j}^{1}+f_{i j}^{2}=f_{i j}$.

Para que o modelo possa considerar $w_{i j}$ ou $w_{i j}^{2}$, é necessário introduzir as seguintes restrições para o ativo com carência para o resgate:

$$
\begin{aligned}
& f_{i j}^{1}+f_{i j}^{2}=f_{i j},(i, j)=(i, i+1) \mathrm{e}(i, i+2), i=1, \ldots, \dot{n}-1 e i=1,2, \ldots, n-2 \\
& 0 \leq f_{i j}^{1}<\operatorname{lm}_{i j} x_{i j}^{1},(i, j)=(i, i+1) \mathrm{e}(i, \hat{\imath}+2), i=1, \ldots, n-1 e i=1,2, \ldots, n-2 \\
& \operatorname{lm}_{i j} x_{i j}^{2} \leq f_{i j}^{2} \leq M x_{i j}^{2},(i, j)=(i, i+1) \mathrm{e}(i, \hat{\imath}+2), i=1, \ldots, \dot{n}-1 e i=1,2, \ldots, n-2 \\
& x_{i j}^{1}+x_{i j}^{2}=1 \\
& x_{i j}^{1}, x_{i j}^{2} \in\{0,1\},(i, j)=(i, i+1) \mathrm{e}(i, i+2), i=1, \ldots, n-1 o u i=1,2, \ldots, n-2
\end{aligned}
$$

Essas restrições são válidas para os $\operatorname{arcos}(i, i+1), i=1,2, \ldots, \hat{n}-1$, e os $\operatorname{arcos}$ $(i, i+2), i=1,2, \ldots, n-2$ e garantem que, dependendo do valor investido no ativo com período de carência (menor que $l m_{i j}$ ou maior ou igual do que esse limitante), a remuneração será $w_{i j}$ ou $w_{i j}^{2}$. A notação $M$ define um número suficientemente grande.

Um caso particular desse tipo de abordagem pode ser observado na Figura 4, na qual nenhum rendimento é pago ao investimento no ativo com carência para o resgate se o monte investido for menor do que $l m_{i j}$. Nesse caso, $g_{i j}=w_{i j}^{2} f_{i j}^{2}$ e as restrições adicionais são:

$$
\begin{aligned}
& \operatorname{lm}_{i j} x_{i j}^{2} \leq f_{i j}^{2} \leq M x_{i j}^{2},(i, j)=(i, \hat{\imath}+1) \mathrm{e}(i, \hat{\imath}+2), \hat{\imath}=1, \ldots, \dot{n}-1 e i=1,2, \ldots, n-2 \\
& x_{i j}^{2} \in\{0,1\},(i, j)=(i, \hat{\imath}+1) \mathrm{e}(i, \hat{\imath}+2), \hat{\imath}=\hat{1}, \ldots, \hat{n}-1 e i=1,2, \ldots, n-2
\end{aligned}
$$


Figura 3: Rendimento para o ativo com período de carência em função do valor investido.

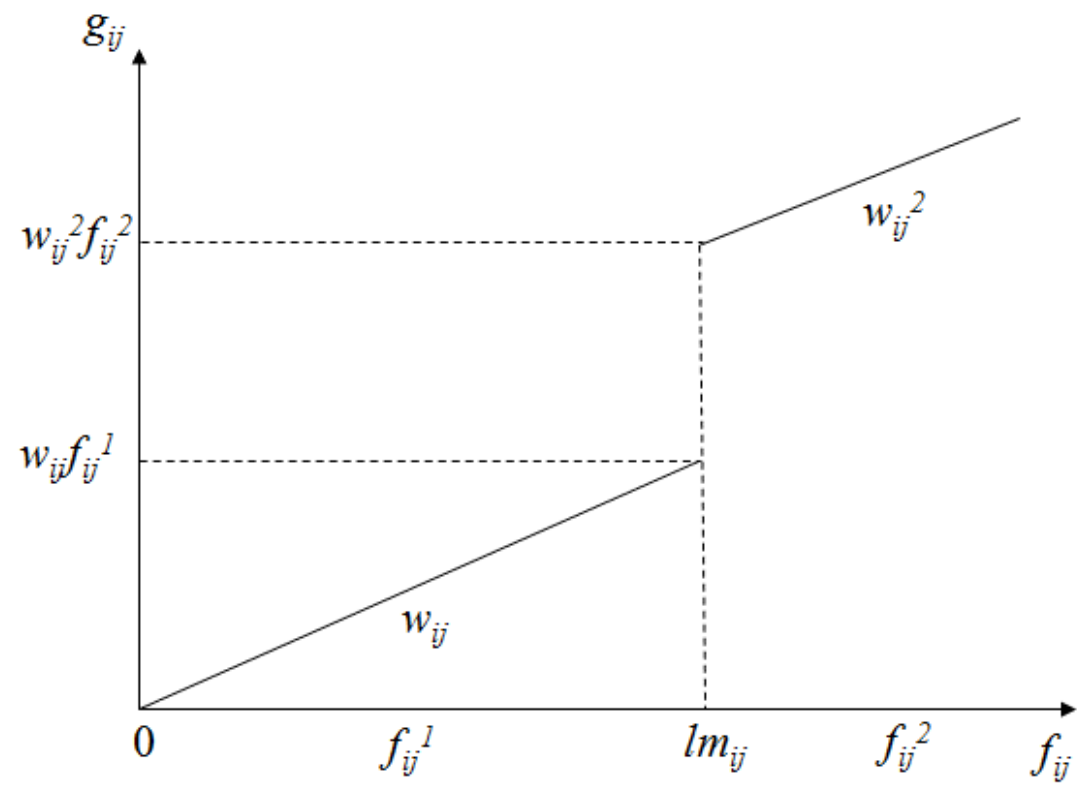

Fonte: Righetto et al., 2016.

Figura 4: Valor mínimo para investimento no ativo com período de carência.

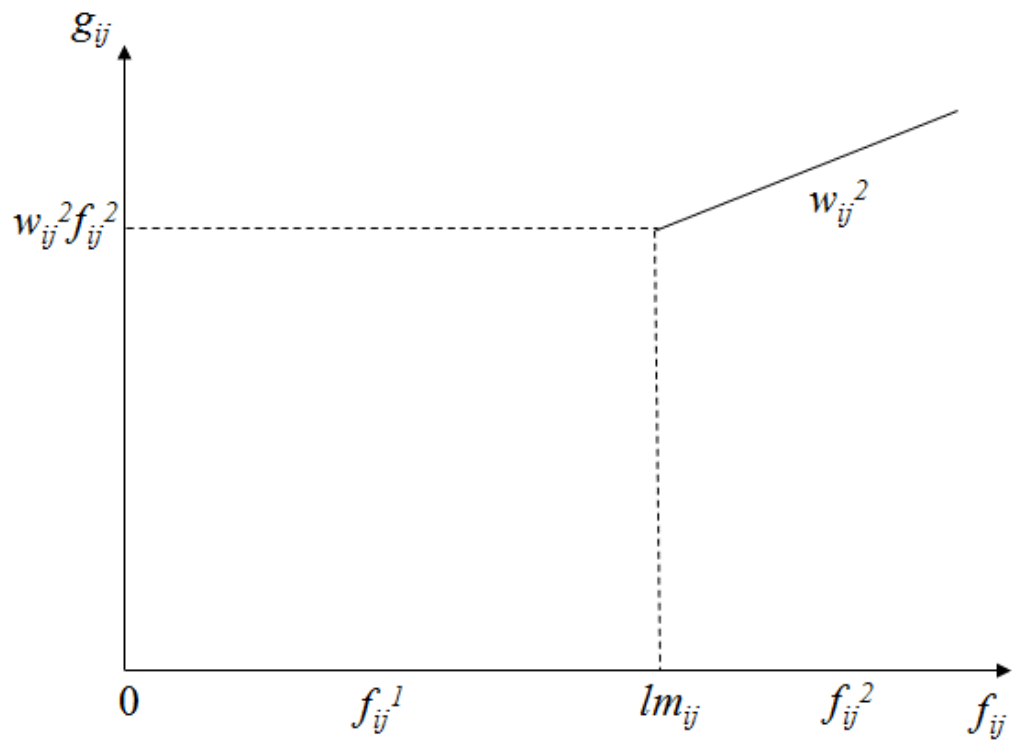

Fonte: Righetto et al., 2016.

Esse caso particular corresponde a um dos cenários alternativos para testar o desempenho do modelo com dados reais da empresa do estudo de caso, conforme é visto na Seção 4.

Conforme ilustrado na Figura 2, os $\operatorname{arcos}(i, \hat{\imath}+1), i=1,2, \ldots, \hat{n}-1$, e os $\operatorname{arcos}$ $(i, \imath+2), i=1,2, \ldots, n-2$ são os investimentos no ativo com carência para o resgate e são utilizados pela empresa para aumentar as suas receitas financeiras e, consequentemente, aumentar a sua lucratividade. Os arcos reversos, $(i+1, i), i=1,2, \ldots n$, representam os 
empréstimos bancários. Os arcos representados por $(i, i+1), i=1,2, \ldots, n-1$, representam a movimentação da conta corrente bancária. Os arcos $(\bar{i}, \bar{i}+1), \bar{i}=\overline{1}, \overline{2}, \ldots, \bar{n}-1$, representam a movimentação das aplicações financeiras com liquidez imediata e os arcos $(i, \hat{\imath}+1), \hat{\imath}=1, \hat{2}, \ldots, \hat{n}-1$, constituem a movimentação das aplicações financeiras com período de carência. Os arcos $(i, \bar{i}),(\bar{i}, i),(i, i)$ representam a conversão de fundos entre os três ativos $a, b$ e $c$. Os outros arcos do conjunto $A,(n-1, Z),(n, Z),(\bar{n}, Z)$ e $(\dot{n}, Z)$, correspondem ao fluxo do último período dos ativos $a, b$ e $c$ para o nó $Z$.

\subsection{Modelo de Programação Linear Inteira Mista}

O conjunto $N^{-}$é o conjunto $N$ sem os nós $s$ e $d$, ou seja, $N^{-N\{s\}\{d\}}$.

As variáveis de decisão do modelo são:

- $f_{i j}$ : fluxos de recursos financeiros que o nó $i$ recebe, $(i, j) \in A, i \in N^{-}, j \in N^{-}$;

- $f_{i j}^{1}$ : é o montante investido menor que $l m_{i j}$, que recebe a rentabilidade representada pelo multiplicador $w_{i j}$;

- $f_{i j}^{2}$ : é o montante investido maior ou igual a $l m_{i j}$, que recebe a rentabilidade $w_{i j}^{2}$;

- $x_{i j}^{1}$ : variável binária igual a 1 quando $0 \leq f_{i j}<l m_{i j}$, para $(i, i+1), i=1,2, \ldots, \dot{n}-1$, e $(i, i+2), i=1,2, \ldots, n-2 ; \mathrm{e}$

- $\quad x_{i j}^{2}$ : variável binária igual a 1 quando $l m_{i j} \leq f_{i j} \leq M,(i, i+1), i=1,2, \ldots, \dot{n}-1$, e

- $(i, i+2), i=1,2, \ldots, n-2 ; \mathrm{e}$

Os parâmetros do modelo estão descritos a seguir:

- $\quad a$ : ativo considerado como meio de troca, ou seja, dinheiro;

- $\quad b$ : aplicações financeiras sem prazo de carência para o resgate;

- $\quad c$ : aplicações financeiras com prazo de carência para o resgate;

- $\alpha_{i j}$ : rendimento dos juros por período gerado pelo ativo $a$, para $(i, j)=(i, i+1), i=1,2, \ldots, n-1 e(n, Z)$;

- $\beta_{i j}$ : rendimento dos juros por período gerados pelo ativo $b$, para $(i, j)=(\bar{i}, \bar{i}+1) e(\bar{n}, Z), \bar{i}=\overline{1}, \overline{2}, \ldots, \bar{n}-1$;

- $\varepsilon_{i j}$ : rendimento dos juros por período gerados pelo ativo $c$, para $(i, j)=(i, i+1) \mathrm{e}(i, i+$ 2)e $(\dot{n}, Z) e 0 \leq f_{i j} \leq \operatorname{lm}_{i j}, i=1, \ldots, n-1 e$ $i=1,2, \ldots, n-2$;

- $\kappa_{i j}$ : rendimento dos juros por período gerados pelo ativo $c$, para $(i, j)=(i, i+1) \mathrm{e}(i, i+$ 2)e $(\dot{n}, Z) e l m_{i j} \leq f_{i j} \leq M, i=1, \ldots, n-1 e$ $i=1,2, \ldots, n-2$;

- $\gamma_{i j}$ : juros incorridos pela utilização do ativo $a$, para $(i, j)=(i+1, i), i=2, \ldots, n$. São os juros pagospelautilização do empréstimo bancário;

- $c_{a b}$ : custo unitário de conversão do ativo apara o ativo $b$;

- $c_{a c}$ : custo unitário de conversão do ativo apara o ativo $c$;

- $c_{b a}$ : custo unitário de conversão do ativo bpara o ativo $a$;

- $c_{c a}$ : custo unitário de conversão do ativo cpara o ativo $a$;

- $a_{0}$ : saldo inicial do ativo $a$;

- $b_{0}$ : saldo inicial do ativo $b$;

- $c_{0}$ : saldo inicial do ativo $c$;

- $s_{i}$ : entradas de caixa, para $i=1,2, \ldots, n$;

- $d_{i}$ : saídas de caixa, para $i=1,2, \ldots, n$;

- $w_{i j}$ : multiplicador dos fluxos de recursos nos $\operatorname{arcos}(i, j)$;

- $w_{i j}^{2}$ : multiplicador dos fluxos de recursos nos $\operatorname{arcos}(i, j)$, para $(i, j)=(i, i+1) \mathrm{e}(i, i+$ 2)e $(\dot{n}, Z) e l m_{i j} \leq f_{i j} \leq M, \dot{\imath}=\dot{1}, \ldots, \hat{n}-1 e$ $i=1,2, \ldots, n-2$;

- $u_{i j}$ : limite máximo de endividamento, para $(i, j)=(i+1, i), i=2, \ldots, n$; 
- $m_{i j}$ : limite mínimo de caixa, para $(i, j)=(i, i+1), i=1,2, \ldots, n-1 e(n, Z)$;

- $q_{i j}$ : limite mínimo para o ativo $b$, para $(i, j)=(\bar{i}, \bar{i}+1) e(\bar{n}, Z), \bar{i}=\overline{1}, \overline{2}, \ldots, \bar{n}-1$;

- $\quad l m_{i j}$ : limite máximo para o ativo $c$ receber o rendimento $\varepsilon_{i j}$ e mínimo para o ativo $c$ receber o rendimento $\kappa_{i j}$, para $(i, j)=(i, i+1) \mathrm{e}(i, \hat{\imath}+2) \mathrm{e}(\dot{n}, Z), i=\hat{1}, \ldots, \dot{n}-1 e i=$ $1,2, \ldots, n-2$;

- $\quad M$ : é um número suficientemente grande que é o limitante para o ativo $c$ receber o rendimento $\kappa_{i j}$, para $(i, j)=(i, i+1)$ ou $(i, \hat{\imath}+2)$ ou $(\dot{n}, Z), i=1, \ldots, \dot{n}-1$ ou $i=1,2, \ldots, n-$ 2.

As restrições para os multiplicadores são:

$$
\begin{aligned}
& w_{i j}= \\
& \left\{\begin{array}{l}
1+\alpha_{i j} \text { para }(i, j)=(i, i+1) \text { e }(n, Z) \\
1+\beta_{i j} \text { para }(i, j)=(\bar{l}, \bar{l}+1) \text { e }(\bar{n}, Z) \\
1+\varepsilon_{i j} \text { para }(i, j)=(\bar{l}, \bar{l}+1) \text { e }(\overline{\bar{n}}, Z) \text { e } 0 \leq f_{i j}^{1} \leq l m_{i j} \\
\left(1+\varepsilon_{i j}\right)^{2} \text { para }(i, j)=(i, \bar{l}+2) \text { e } 0 \leq f_{i j}^{1} \leq l m_{i j} \\
1-C_{a b} \text { para }(i, j)=(i, \bar{l}) \\
1-C_{a c} \text { para }(i, j)=(i, \bar{l}+2) \\
1-C_{b a} \text { para }(i, j)=(\bar{l}, i) \\
1-C_{c a} \text { para }(i, j)=(\bar{l}, i) \\
\frac{1}{1+\gamma_{i j}} \text { para }(i, j)=(i+1, i)
\end{array}\right.
\end{aligned}
$$
financeiros é:

O modelo de programação linear inteira mista para a maximização do fluxo de recursos

Maximizar $w_{n-1, z} f_{n-1, z}^{1}+w_{n-1, z}^{2} f_{n-1, z}^{2}+w_{n z} f_{n z}^{1}+w_{n z}^{2} f_{n z}^{2}+w_{\bar{n} z} f_{\bar{n} z}+w_{n, Z} f_{n z}^{1}+w_{\dot{n} z}^{2} f_{\dot{n} z}^{2}$

Sujeito a:

$$
\begin{aligned}
& \sum_{j \in N^{-}} w_{j i} f_{j i}-\sum_{j \in N^{-}} f_{i j} \geq-a_{0}-s_{i}+d_{i}, i=1 \\
& \sum_{j \in N^{-}} w_{j i} f_{j i}-\sum_{j \in N^{-}} f_{i j} \geq-b_{0}, i=\overline{1} \\
& \sum_{j \in N^{-}} w_{j i} f_{j i}-\sum_{j \in N^{-}} f_{i j} \geq-c_{0}, i=\overline{\overline{1}} \\
& \sum_{j \in N^{-}} w_{j i} f_{j i}-\sum_{j \in N^{-}} f_{i j} \geq-s_{i}+d_{i}, i=2,3, \ldots, n \\
& \sum_{j \in N^{-}} w_{j i} f_{j i}-\sum_{j \in N^{-}} f_{i j} \geq 0, i=\overline{2}, \overline{3}, \ldots, \bar{n} \\
& \sum_{j \in N^{-}} w_{j i} f_{j i}^{1}+\sum_{j \in N^{-}} w_{j i}^{2} f_{j i}^{2}-\sum_{j \in N^{-}} f_{i j} \geq 0, i=\overline{\overline{2}}, \overline{\overline{3}}, \ldots, \overline{\bar{n}} \\
& f_{n-1, z}^{1}+f_{n-1, z}^{2}=f_{n-1, z} \\
& f_{n z}^{1}+f_{n z}^{2}=f_{n z} \\
& f_{\bar{n} z}^{1}+f_{\bar{n} z}^{2}=f_{\bar{n} z} \\
& 0 \leq f_{n-1, z}^{1} \leq \operatorname{lm} m_{n-1, z} x_{n-1, z}^{1} \\
& l m_{n-1, z} x_{n-1, z}^{2} \leq f_{n-1, z}^{2} \leq M x_{n-1, z}^{2} \\
& 0 \leq f_{n z}^{1} \leq \operatorname{lm} m_{n z} x_{n z}^{1}
\end{aligned}
$$




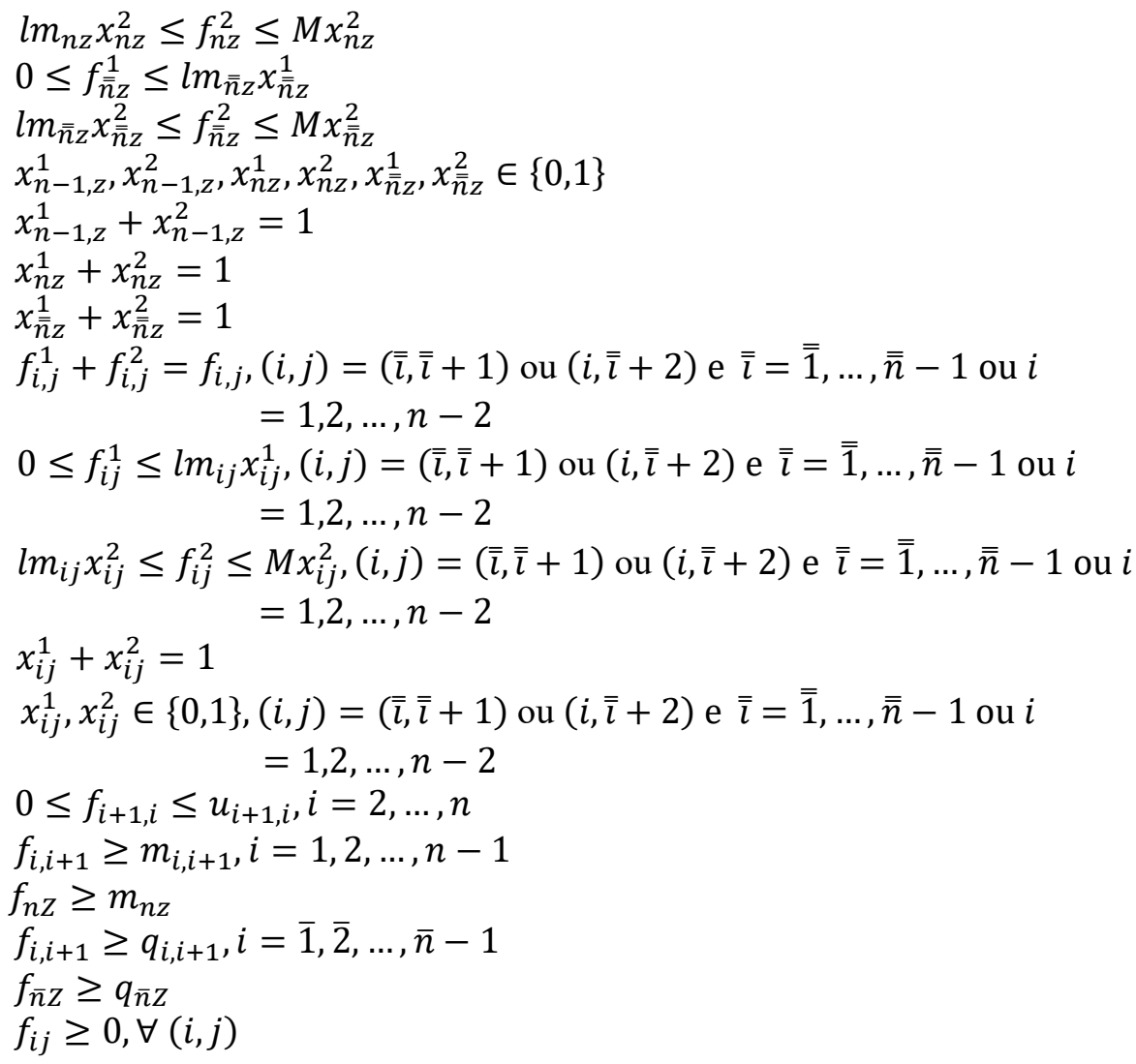

A função objetivo (15) maximiza o montante de recursos financeiros no nó $z$, que estão aplicados nos ativos $a, b$ e $c$, considerando os correspondentes multiplicadores $w_{i j}$. Os dois primeiros termos da função objetivo, $w_{n-1, z} f_{n-1, z}^{1} e w_{n-1, z}^{2} f_{n-1, z}^{2}$, são os fluxos de recursos que chegam ao nó terminal $z$ por meio do penúltimo nó do ativo $a$. Esses fluxos chegam ao nó $z$, multiplicados por $w_{n-1, z}$ ou por $w_{n-1, z}^{2}$, dependendo do valor investido. As restrições que determinam o rendimento do fluxo $f_{n-1, z}$ são (22), (25), (26), (31) e (32). O terceiro e quarto termos da função objetivo (15), $w_{n z} f_{n z}^{1} e w_{n z}^{2} f_{n z}^{2}$, são os fluxos de recursos que chegam ao nó terminal $z$ por meio do último nó do ativo $a$. Eles, também, dependem do valor investido e as restrições que determinam o rendimento para $f_{n z}$ são (23), (27), (28), (33) e (42). O quinto termo da função objetivo (15), é o fluxo de recursos que chega ao nó $z$ por meio do ativo $b$, que tem liquidez imediata. Como esse ativo não tem a possibilidade de obter diferentes rendimentos, dependendo do valor investido, ele não necessita das restrições utilizadas para o ativo $a$. Os dois últimos termos da função objetivo (15), $w_{n, z} f_{n z}^{1}+w_{n z}^{2} f_{n z}^{2}$, são os fluxos que chegam ao nó terminal $z$ por meio do ativo $c$. Esses fluxos dependem do valor investido para a determinação dos seus rendimentos e as restrições que controlam essa dependência são (24), (29), (30) e (34).

A restrição (16) representa o balanço de fluxo para o nó 1 . Nessa restrição, são considerados o saldo inicial do ativo $a$, as entradas de caixa, $s_{i}$, e as saídas de caixa, $d_{i}$, além da movimentação do ativo no tempo e o empréstimo bancário. A restrição (17) representa o balanço de fluxo para o nó $\overline{1}$. Além da movimentação do ativo, considera-se o saldo inicial do ativo $b$. A restrição (18) representa o balanço de fluxo para o nó 1́. Nessa expressão, são consideradas as movimentações do ativo $c$, bem como o seu saldo inicial. A restrição (19) é o balanço de fluxo para os nós $2,3, \ldots, n$. Nessa expressão, são consideradas as entradas e saídas de caixa, $s_{i}$ e $d_{i}$, respectivamente, a movimentação do ativo $a$, e os empréstimos bancários. As restrições (20) e (21) representam o balanço de fluxo para os nós $\overline{2}, \overline{3}, \ldots, \bar{n}$ e para os nós $2,3, \ldots, n$, respectivamente. As restrições (35), (36), (37), (38) e (39) são aquelas necessárias para considerar a função convexa linear por partes da programação inteira mista para $(i, j)=(i, i+1) \mathrm{e}(i, \hat{\imath}+2) e \hat{\imath}=\hat{1}, \ldots, \dot{n}-$ 
1 oui $=1,2, \ldots, n-2$. A restrição (40) representa o limite máximo de endividamento e a condição de não negatividade dos empréstimos bancários. As restrições (41) e (42) indicam o saldo mínimo de caixa e as equações (43) e (44) indicam o saldo mínimo para a aplicação no CDB sem carência para o resgate. Conforme já salientado no início do capítulo, esses saldos mínimos são necessários para garantir uma condição mínima de liquidez para qualquer eventualidade na economia, como, por exemplo, uma restrição de crédito por parte dos bancos. A restrição (45) é a condição de não negatividade das variáveis para todo tipo de arco $(i, j)$.

\section{Aplicação na Empresa Estudada}

\subsection{Estudo de Caso}

A empresa estudo de caso escolhida para aplicação e análise da abordagem é uma típica representante do setor de material escolar. Para mais detalhes sobre essa empresa e seu problema de fluxo de caixa, ver Righetto (2015). Para essa empresa, os dados de entrada do modelo de otimização foram distorcidos para a preservação da confidencialidade da fonte e proteger seus interesses.

O modelo matemático foi codificado na linguagem de modelagem algébrica GAMS 23.0.2 e resolvido pelo solver de otimização CPLEX 11.2 com parâmetros default. O computador utilizado para os testes computacionais foi um notebook com processador Intel(R) Core(TM) i3-3110M, 2.40GHz e memória RAM de 4GB. Por simplicidade, os valores monetários são apresentados em milhares de reais no restante deste texto. No exemplo fornecido pela empresa estudada, o horizonte de planejamento envolve 12 períodos (meses). O cálculo das taxas de juros mensais baseia-se num ano de 252 dias úteis (DU). Os dias úteis de cada período de um mês $(t=1,2, \ldots, 12)$ são exibidos na Tabela 1 .

Tabela 1: Número de dias úteis por período (mensal).

\begin{tabular}{ccccccccccccc}
\hline $\begin{array}{c}\text { Período } \\
\text { (mês) }\end{array}$ & 1 & 2 & 3 & 4 & 5 & 6 & 7 & 8 & 9 & 10 & 11 & 12 \\
Dias úteis & 20 & 22 & 20 & 22 & 23 & 19 & 22 & 20 & 20 & 22 & 18 & 20 \\
\hline \multicolumn{1}{c}{ Fonte: Righetto et al., 2016.}
\end{tabular}

Para o cálculo da taxa de juros nos 12 períodos, consideraram-se as seguintes informações:

- $\quad l_{a . m .}$ : taxa de juros mensal, baseada nos DU de cada mês;

- $\iota_{\text {a.a. }}$ : taxa de juros anual, baseada em um ano com 252 DU;

- \%CDI: porcentagem acima da taxa estipulada para o Certificado de Depósito Interbancário (taxa de juros praticada no mercado interbancário brasileiro);

- $D U_{t}$ : dias úteis em cada mês $t$;

A expressão do cálculo da taxa de juros mensal é definida a seguir (Assaf Neto, 2018):

$$
\left.\iota_{\text {a.m. }}=\left(\left(\left(\left(1+\iota_{\text {a.a. }}\right)^{\frac{1}{252}}-1\right)\right) \% C D I+1\right)^{D U_{t}}-1\right) \times 0,785
$$

A multiplicação por 0,785 é explicada pela cobrança de $22,5 \%$ de imposto de renda retido na fonte sobre o valor do rendimento da aplicação, cobrado no momento do resgate dos recursos aplicados. Dessa forma, o juro efetivamente recebido, ou seja, aquele que está disponível para a empresa, é 22,5\% menor, ou representa 78,5\% do rendimento bruto da aplicação financeira.

Os Certificados de Depósito Interbancário (CDI) são os títulos de emissão das instituições financeiras, que lastreiam as operações do mercado interbancário. Uma aplicação financeira que rende $100 \%$ do CDI terá exatamente a mesma rentabilidade da variação do CDI em determinado período. Se o CDI teve uma taxa acumulada de $11,65 \%$ nos últimos 12 meses, essa aplicação teria rendido exatamente $11,65 \%$ no mesmo período. Caso uma aplicação financeira renda $90 \%$ ou 
$110 \%$ do CDI, e o rendimento do CDI foi de $11,60 \%$ nos últimos 12 meses, a rentabilidade desse investimento, no mesmo período, teria sido $10,44 \%(11,60 \% \times 90 \%)$ e $12,76 \%(11,60 \% \times$ $110 \%)$, respectivamente. A Tabela 2 apresenta as taxas de juros ao ano previstas para os 12 períodos considerados nessa análise.

Tabela 2: Taxa de juros em base anual para cada mês do período considerado.

\begin{tabular}{ccccccccccccc}
\hline Período & 1 & 2 & 3 & 4 & 5 & 6 & 7 & 8 & 9 & 10 & 11 & 12 \\
$\begin{array}{c}\text { Dias úteis } \\
100 \% \text { CDI }\end{array}$ & 20 & 22 & 20 & 22 & 23 & 19 & 22 & 20 & 20 & 22 & 18 & 20 \\
\begin{tabular}{c} 
a.a. \\
\hline
\end{tabular} & $9,19 \%$ & $8,72 \%$ & $8,35 \%$ & $8,02 \%$ & $7,78 \%$ & $7,36 \%$ & $7,18 \%$ & $7,18 \%$ & $7,18 \%$ & $7,18 \%$ & $7,18 \%$ & $7,18 \%$ \\
\hline
\end{tabular}

Fonte: Righetto et al., 2016.

Essas taxas servem de base para o cálculo das aplicações financeiras e do empréstimo bancário. Para o ativo $b$, a porcentagem do CDI considerada para o cálculo dos juros, $\beta_{i j}$, é de $98 \%$. Como a liquidez dessa aplicação financeira é imediata, ou seja, não existe nenhum tipo de carência para o seu resgate, a rentabilidade desse tipo de aplicação financeira é abaixo da taxa do CDI. Para a aplicação financeira que possui dois períodos de carência e para o estoque de aplicação financeira cujo período de carência já expirou a porcentagem do CDI para o cálculo dos juros, $\varepsilon_{i j}$, é de $103 \%$ do CDI. No caso de o valor da aplicação exceder o valor de $l m_{i j}$, esse percentual sobe para 106\% do CDI. Para os empréstimos, é considerada uma taxa de juros, $\gamma_{i j}$, de 109\% do CDI. Para $\alpha_{i j}$, não é considerado nenhum tipo de rendimento, ou seja, o valor atribuído a ele é zero. A Tabela 3 apresenta as taxas de juros praticadas para os ativos $b$ e $c$, líquidos do imposto de renda retido na fonte de $22,5 \%$, e para o empréstimo bancário.

Tabela 3: Taxa de juros mensais por ativo.

\begin{tabular}{crrrrrrrrrrrr}
\hline Período & 1 & 2 & 3 & 4 & 5 & 6 & 7 & 8 & 9 & 10 & 11 & 12 \\
\hline$\beta_{i j}$ & 0,54 & 0,56 & 0,49 & 0,52 & 0,53 & 0,41 & 0,47 & 0,42 & 0,42 & 0,47 & 0,38 & 0,42 \\
$\varepsilon_{i j}$ & 0,57 & 0,59 & 0,52 & 0,55 & 0,56 & 0,43 & 0,49 & 0,45 & 0,45 & 0,49 & 0,40 & 0,45 \\
$\kappa_{i j}$ & 0,58 & 0,61 & 0,53 & 0,56 & 0,57 & 0,45 & 0,51 & 0,46 & 0,46 & 0,51 & 0,41 & 0,46 \\
$\gamma_{i j}$ & 0,76 & 0,80 & 0,70 & 0,74 & 0,75 & 0,59 & 0,66 & 0,60 & 0,60 & 0,66 & 0,54 & 0,60 \\
\hline \multicolumn{1}{c}{ Fonte: Righetto et al., 2016.}
\end{tabular}

No exemplo estudado, o saldo inicial do ativo $a$ é de 1.994 (ou seja, R \$1,994 milhões, dado que os valores monetários estão aqui apresentados em milhares de reais) e as entradas e saídas de caixa em cada período são apresentadas na Tabela 4 (também em milhares de reais). Para o ativo $b$, o saldo inicial é igual zero. Para o estoque de aplicações financeiras cujo prazo de carência já expirou, o saldo inicial é igual a 100.000. Esse estoque ainda vai receber os recursos que estão aplicados com período de carência de dois meses e que são geradas pelo modelo e, portanto, liberadas e adicionadas ao estoque de aplicações financeiras com período de carência expirado, para que sejam passíveis de resgate.

Tabela 4: Entradas e saídas de caixa em milhares de reais.

\begin{tabular}{rrrrrrrrrrrrr}
\hline Período & 1 & 2 & 3 & 4 & 5 & 6 & 7 & 8 & 9 & 10 & 11 \\
\hline$S_{i}$ & 14.784 & 14.949 & 14.250 & 13.972 & 12.915 & 20.423 & 13.675 & 21.260 & 17.659 & 141.499 & 120.000 & 125.000 \\
$d_{i}$ & 89.159 & 7.828 & 18.009 & 19.200 & 15.359 & 42.856 & 9.294 & 17.332 & 6.016 & 50.689 & 95.362 & 140.035 \\
\hline
\end{tabular}

Fonte: Righetto et al., 2016.

Os custos para aplicações de recursos nos ativos $b$ e $c$ são $C_{(a, b)} C_{(a, c)}=0$. Os custos de resgatar recursos dos ativos $b$ e $c$ são (já que se considera o juro líquido de imposto de renda retido na fonte) $C_{(b, a)}=C_{(c, a)}=0$. Para os empréstimos bancários, existe o limite máximo de 100.000. Assume-se que, uma vez contratado o empréstimo, o pagamento do valor contratado 
mais os juros devem ocorrer no período imediatamente posterior. Assim sendo, as opções existentes para a movimentação financeira desse horizonte de planejamento são: manter saldo em conta corrente, destinar fundos às aplicações financeiras disponíveis e utilizar a linha de crédito para cobertura de fluxos de caixa líquidos negativos.

\subsection{Resultados Computacionais}

Sendo o fluxo líquido de caixa negativo, a necessidade de caixa deve ser atendida por meio das opções disponíveis: saldo anterior em caixa, resgate de aplicação financeira e/ou linha de crédito. Como dados de entrada, todas as transações ocorrem no início do período a que estão ligadas, sejam elas as entradas e saídas de caixa, bem como os arcos horizontais e verticais. A Figura 5 apresenta a solução ótima do modelo determinístico de fluxos em rede. Os valores nos arcos representam os fluxos das variáveis de decisão $f_{i j}$.

Como era esperado, a solução ótima do modelo aloca a maior parte dos investimentos no ativo $c$, que possui carência para o resgate, pagando um rendimento maior que o ativo $b$. Os montantes que saem do nó 11 e 12 chegam no nó terminal $z$ diretamente, sem passar pelos ativos $b$ ou $c$, já que o horizonte de planejamento termina no período 12 e são remunerados a um percentual de $106 \%$ do CDI, já que são valores maiores do que cinco milhões de reais. O nó terminal recebe recursos do nó 11, 12, $\overline{12}$ e 12, cujos valores são 42.513, 72.627, 2.000 e 5.000 , respectivamente. Esses valores chegam no nó terminal com os seus respectivos multiplicadores. Dessa forma, o valor da função objetivo é de 123.886 .

É interessante observar que, para esse mesmo exemplo, a solução utilizada pela tesouraria da empresa resultou em um valor de 123.831. A Figura 6 apresenta a solução empregada pela empresa. Note que existem várias diferenças entre a solução determinística do modelo inteiro misto e a solução da tesouraria da empresa.

A tesouraria da empresa, que conta com profissionais experientes no mercado financeiro, com mais de 15 anos de experiência nessas atividades, demora em torno de duas a três horas para elaborar o fluxo e realizar todos os cálculos necessários para gerar a solução do problema. O modelo determinístico de otimização linear inteira mista foi resolvido otimamente em menos de um segundo em cada uma das simulações realizadas, pelo solver utilizado, facilitando a tomada de decisão por parte do gestor financeiro. O número total de variáveis foi de 1.666, sendo que dentre estas existem 48 variáveis inteiras. O número de restrições é de 29.004. A tesouraria da empresa estudou e calculou novamente o fluxo de caixa e concordou que a solução proposta pelo modelo determinístico foi um pouco melhor do que a solução gerada por ela, validando a solução e a lógica do modelo para a utilização prática na empresa.

Note que o ganho financeiro obtido pelo modelo determinístico não é relevante neste exemplo. No entanto, além do pequeno aumento de recursos financeiros no nó objetivo, o modelo gera uma nova forma de gerenciar o caixa, com aumento da segurança e velocidade na análise do problema, bem como permite a sistematização do processo da gestão do fluxo de caixa, uma vez que a solução do modelo é menos dependente da experiência dos analistas da tesouraria da empresa. Ademais, a cada mudança de cenário nos dados de entrada, o modelo gera rapidamente a solução otimizada. Essa rapidez é muito importante para os tomadores de decisão, já que, em muitos casos, os parâmetros do modelo são forçados a variar para gerar cenários de choque, no intuito de analisar os impactos financeiros de mudanças no fluxo de caixa da empresa.

Outros exemplos da empresa também foram analisados por meio do modelo determinístico inteiro misto e comparados com as soluções da tesouraria. Os resultados dessas comparações foram similares ao exemplo ilustrativo anterior, mostrando a consistência e a acurácia do modelo para representar apropriadamente o problema do fluxo de caixa e gerar soluções competitivas em relação às soluções apresentadas pela tesouraria. 
Figura 5: Resultado de solução ótima do modelo determinístico.

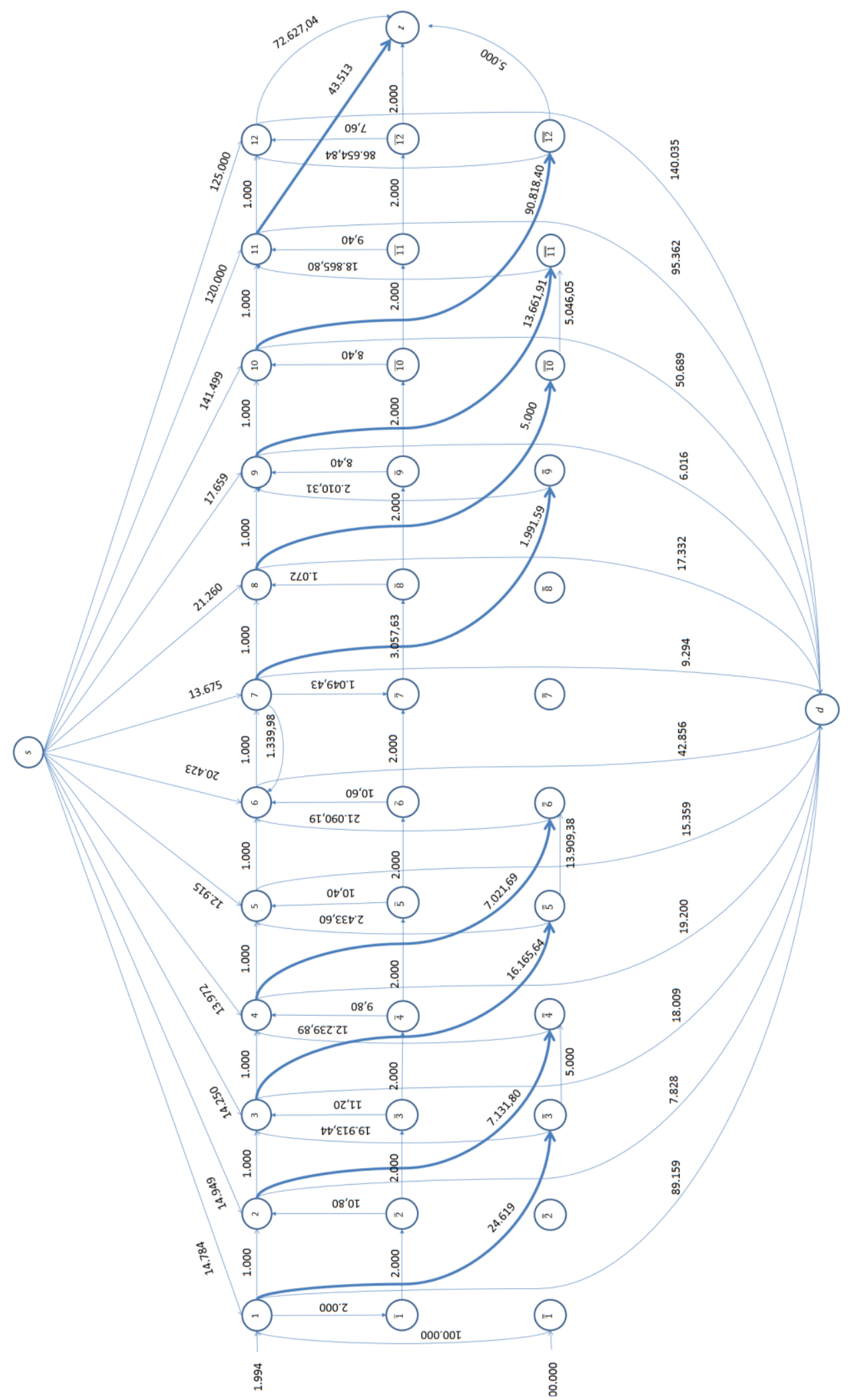

Fonte: Righetto et al., 2016. 
Figura 6: Resultado da solução da tesouraria da empresa.

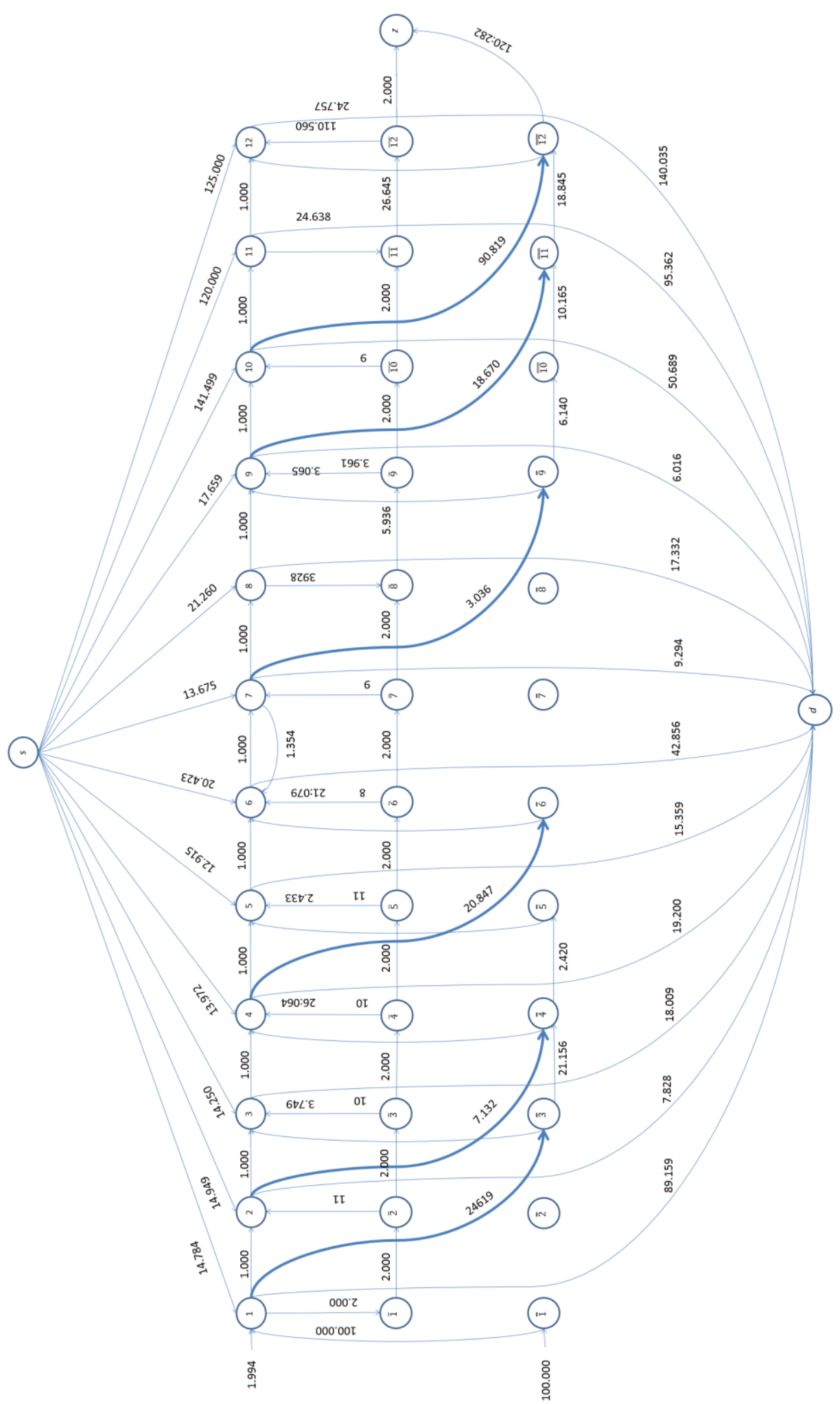

Fonte: Righetto et al., 2016. 


\section{Conclusões}

Nesse trabalho, propõe-se uma abordagem de otimização para representar e resolver o problema de maximização dos recursos financeiros disponíveis no final de um horizonte de planejamento de caixa em empresas do setor de material escolar. Essa abordagem pode ser útil para analisar o problema nos parâmetros que definem esse fluxo e apoiar decisões de gestão de caixa nestas empresas. Foi desenvolvida uma formulação linear inteira mista do problema de fluxos em rede determinística para o planejamento tático do fluxo de caixa, que tem como diferencial em relação aos modelos anteriores já propostos na literatura os títulos negociáveis com carência para o resgate e a possibilidade de obter um rendimento maior, dependendo do valor investido.

$\mathrm{O}$ ganho financeiro obtido resolvendo-se otimamente o modelo inteiro misto determinístico em relação ao método adotado pela tesouraria da empresa estudada não foi muito relevante nos exemplos da empresa aqui estudados. No entanto, em que pese o pequeno aumento de recursos financeiros no nó objetivo, o modelo de otimização utilizado apresentou uma nova forma de gerenciar o caixa, com aumento da segurança e velocidade na análise do problema, bem como contribuiu para a sistematização do processo da gestão do fluxo de caixa, uma vez que a solução do modelo é menos dependente da experiência dos analistas da tesouraria da empresa.

Ademais, a cada mudança de cenário nos dados de entrada, o modelo inteiro misto gera rapidamente uma nova solução otimizada. Essa rapidez e precisão são muito importantes para os tomadores de decisão, já que, em muitos casos, os parâmetros do modelo são forçados a variar para gerar diversos cenários de choque e realizar análises de sensibilidade, no intuito de avaliar os impactos financeiros de possíveis mudanças no fluxo de caixa da empresa. Esses benefícios foram considerados importantes pelos tomadores de decisão da empresa.

A realização de experimentos computacionais com outros exemplos desta e de outras empresas do setor de material escolar com o modelo e a abordagem proposta neste artigo é um tópico de pesquisa futura para poder obter avaliações mais conclusivas sobre o desempenho do modelo neste problema de fluxo de caixa. Como os parâmetros que definem os fluxos de recursos no problema do fluxo de caixa tático em geral contém incertezas, o desenvolvimento de modelos baseados em programação estocástica e otimização robusta (Birge e Louveaux, 1997; Bertsimas e Sim, 2004), que considerem essas incertezas nos parâmetros do problema do fluxo de caixa, são tópicos interessantes para pesquisas e aplicações futuras (Righetto et al., 2016, 2020).

\section{Referências}

Ahmad, N. N., Ahmad, S. e Abdullah, W. M. T. W. Sustaining SMEs through resources availability and cash management practices: An application of the partial least squares (PLS). Global Business and Management Research: An International Journal, v. 10, n. 3, p. 24-35, 2018.

Alimardani, M. Stochastic mixed-integer programming for financial planning problems using network flow structure. 97 f. Dissertação (Mestrado em Ciências Aplicadas) - Departamento de Engenharia Mecânica e Industrial, Universidade de Toronto, Toronto, Canadá, 2014.

Ashford, R. W., Berry, R. H. e Dyson, R. G. Operational research and financial management. European Journal of Operational Research, v. 36, n. 2, p. 143-152, 1988.

Assaf Neto, A. Mercado Financeiro. 14ª ed. Atlas, 2018.

Baumol, W. The transaction demand for cash: An inventory theoretic approach. The Quarterly Journal of Economics, v. 66, n. 4, p. 545-556, 1952.

Beranek, W. Analysis for Financial Decisions. 2ª ed. R. D. Irwin, Incorporated, 1963.

Bertsimas, D. e Sim, M. The price of robustness. Operations Research, v. 52, n. 1, p. 35-53, 2004. 
Birge, J. R. e Louveaux, F. Introduction to Stochastic Programming. Springer, 1997.

Brigham, E. F. e Houston, J. F. Fundamentals of Financial Management. Thompson/South-Western, 2004.

Calman, R. F. Linear Programming and Cash Management/CASH ALPHA. Cambridge: The MIT Press, 1968.

Crum, R. L., Klingman, D. D. e Tavis, L. A. Implementation of large-scale financial planning methods: solution efficient transformations. Journal of Financial and Quantitative Analysis, v. 14, n. 1, p. 137-152, 1979.

Crum, R. L. e Nye, D. J. A network model of insurance company cash flow management. In: Klingman, D., Mulvey, J. M. (eds.) Network Models and Associated Applications. Mathematical Programming Study, vol. 15, p. 86-101. Springer, 1981.

Damasceno, D. L., Artes, R. e Minardi, A. M. A. F. Determinação de rating de crédito de empresas brasileiras com a utilização de índices contábeis. Revista de Administração - RAUSP, v. 43, n. 4, p. 344-355, 2008.

Geunes, J. e Pardalos, P. M. Network optimization in supply chain management and financial engineering: An annotated bibliography. Networks, v. 42, n. 2, p. 66-84, 2003.

Gitman, L. J. Princípios de Administração Financeira. $3^{\mathrm{a}}$ ed. São Paulo: Harbra, 1997.

Golden, B., Liberatore, M. e Lieberman, C. Models and solution techniques for cash flow management. Computers \& Operational Research, v. 6, n. 1, p. 13-20, 1979.

Gupta, S. e Dutta, K. Modeling of financial supply chain. European Journal of Operational Research, v. 211, n. 1, p. 47-56, 2011.

Jorjani, S. e Lamar, B. W. Cash flow management network models with quantity discounting. Omega, v. 22, n. 2, p. 149-155, 1994.

Mcbride, R. D. e O'Leary, D. E. An intelligent modeling system for generalized network flow problems: With application to planning for multinational firms. Annals of Operations Research, v. 75 , p. 355-372, 1997.

Mulvey, J. M. e Vladimirou, H. Stochastic network programming for financial planning problems. Management Science, v. 38, n. 11, p. 1642-1664, 1992.

Mulvey, J.M. Introduction to the special issue on finance. Interfaces, 24(3), 1-2, 1994.

Orgler, Y. E. An unequal-period model for cash management decisions. Management Science, v. 16, n. 2, p. B-77-B-92, 1969.

Pacheco, J. V. A. e Morabito, R. Application of network flow models for the cash management of an agribusiness company. Computers \& Industrial Engineering, v. 61, n. 3, p. 848-857, 2011.

Righetto, G. M. Abordagens de fluxos em redes utilizando otimização robusta e programação estocástica na gestão financeira do caixa de empresas de material escolar. $148 \mathrm{f}$. Tese (Doutorado em Engenharia de Produção) - Departamento de Engenharia de Produção, Universidade Federal de São Carlos, São Carlos-SP, 2015. 
Righetto, G. M., Morabito, R. e Alem, D. A robust optimization approach for cash flow management in stationery companies. Computers \& Industrial Engineering, v. 99, p. 137-152, 2016.

Righetto, G. M., Morabito, R. e Alem, D. Cash flow management by risk-neutral and risk-averse stochastic approaches. Journal of the Operational Research Society, v. 71, n. 1, p. 55-68, 2020.

Robicheck, A. A., Teichroew, D. e Jones, J. M. Optimal short-term financing decisions. Management Science, v. 12, n. 1, p. 1-36, 1965.

Salas-Molina, F., Rodriguez-Aguilar, J. A., Pla-Santamaria, D. e García-Bernabeu, A. On the formal foundations of cash management systems. Operational Research, 2019. https://doi.org/10.1007/s12351-019-00464-6.

Scherr, F. C. Modern Working Capital Management: Text and Cases. New Jersey: Prentice-Hall, 1989.

Schroeder, P. e Kacem, I. Optimal cash management with uncertain, interrelated and bounded demands. Computers \& Industrial Engineering, v. 133, p. 195-206, 2019.

Schroeder, P. e Kacem, I. Competitive difference analysis of the cash management problem with uncertain demands. European Journal of Operational Research, v. 283, n. 3, p. 1183-1192, 2020.

Sethi, S. P. e Thompson, G. L. Application of mathematical control theory to finance: Modelling simple dynamic cash balance problems. Journal of Financial and Quantitative Analysis, v. 5, n. $4 / 5$, p. 381-394, 1970.

Sousa, A. F. e Barros, L.A. Propriedades estatísticas dos fluxos de caixa e modelos de gerenciamento de caixa. Caderno de Pesquisas em Administração, v.1, n. 12, p. 22-35, 2000.

Srinivasan, V. A transshipment model for cash management decisions. Management Science, v. 20, n. 10, p. 1350-1363, 1974.

Srinivasan, V. e Kim, Y. H. Deterministic cash flow management: State of the art and research directions. Omega, v. 14, n. 2, p. 145-166, 1986.

Steuer, R. E. e Na, P. Multicriteria decision making combined with finance: A categorized bibliographic study. European Journal of Operational Research, v. 150, n. 3, p. 496-515, 2003.

Tabei, S. M. A., Bagherpour, M. e Mahmoudi, A. Application of fuzzy modelling to predict construction projects cash flow. Periodica Polytechnica Civil Engineering, v. 63, n. 2, p. 647-659, 2019.

Tobin, J. The interest-elasticity of transaction demand for cash. The Review of Economic and Statistics, v. 38, n. 3, p. 241-247, 1956.

Van Horne, J. C. Financial Management and Policy. Englewood Cliffs: Prentice-Hall, 1995.

Welsch, G. A., Hilton, R. W. e Gordon, P. N. Budgeting Profit Planning and Control. Englewood Cliffs: Prentice-Hall, 1988.

Yu, J.-R, Chiou, W.-J. P. e Liu, R.-T. Incorporating transaction costs, weighting management, and floating required return in robust portfolios. Computers \& Industrial Engineering, v. 109, p. 48-58, 2017. 